\title{
Oxidative Priority, Meal Frequency, and the Energy Economy of Food and Activity: Implications for Longevity, Obesity, and Cardiometabolic Disease
}

\author{
Raymond J. Cronise, BS, David A. Sinclair, PhD, ${ }^{2,3}$ and Andrew A. Bremer, MD, PhD 4
}

\begin{abstract}
In most modern societies, the relationship that many individuals have with food has fundamentally changed from previous generations. People have shifted away from viewing food as primarily sustenance, and rather now seek out foods based on pure palatability or specific nutrition. However, it is far from clear what optimal nutrition is for the general population or specific individuals. We previously described the Food Triangle as a way to organize food based on an increasing energy density paradigm, and now expand on this model to predict the impact of oxidative priority and both nutrient and fiber density in relation to caloric load. When combined with meal frequency, integrated energy expenditure, macronutrient oxidative priority, and fuel partitioning expressed by the respiratory quotient, our model also offers a novel explanation for chronic overnutrition and the cause of excess body fat accumulation. Herein, we not only review how metabolism is a dynamic process subject to many regulators that mediate the fate of ingested calories but also discuss how the Food Triangle predicts the oxidative priority of ingested foods and provides a conceptual paradigm for healthy eating supported by health and longevity research.
\end{abstract}

Keywords: oxidative priority, metabolism, obesity, longevity, cardiometabolic disease

\section{Introduction}

$\mathrm{I}$ N JUST OVER TWO CENTURIES, we have advanced from discovering the role of oxygen in respiration to interrogating a complex, molecular biology-based model of cellular respiration, hormonal regulation, and bioenergetics in human physiology and pathophysiology. Over a century ago, food was systematically analyzed for its basic energy components-protein, carbohydrate, and fat-and the bioavailability of this energy quantified as a basis for nutritive economic exchange. Direct and indirect calorimetry experiments on individuals in both long- and short-term respiration chamber studies involving both eating and physical activity have also thoroughly documented energy conservation. Why, then, do popular self-help books, scholarly articles, and media headlines still question the validity of the dietary calorie (technically a kilocalorie [1000 cal] or $\sim 4.2 \mathrm{~kJ}$ ) in predicting energy deficit and accumulated excess? And why, despite more being known about energy management than ever before, does our society appear incapable of managing an otherwise simple energy balance?

For many people in developed nations, their relationship with food is fundamentally different than previous generations, with a shift away from sustenance and toward either pure palatability or specific nutrition (i.e., high-protein diets, low-fat diets, low-carbohydrate diets, or combinations

\footnotetext{
${ }^{1}$ Thermogenex, Huntsville, Alabama.

${ }^{2}$ Department of Genetics, Harvard Medical School, Boston, Massachusetts.

${ }^{3}$ Department of Pharmacology, School of Medical Sciences, The University of New South Wales, Sydney, Australia.

${ }^{4}$ Division of Diabetes, Endocrinology, and Metabolic Diseases, National Institute of Diabetes and Digestive and Kidney Diseases, National Institutes of Health, Bethesda, Maryland.

(C) Raymond J. Cronise, et al., 2017; Published by Mary Ann Liebert, Inc. This Open Access article is distributed under the terms of the Creative Commons License (http://creativecommons.org/licenses/by/4.0), which permits unrestricted use, distribution, and reproduction in any medium, provided the original work is properly credited.
} 
thereof). It is far from clear, however, what optimal nutrition is for the general population or for specific individuals. And, how does one make sense of all the claims of certain dietary patterns in addition to the ubiquitous conflicting advertising adjectives of fresh, organic, gluten free, low fat, low "carb," or sugar free?

As we previously described, ${ }^{1}$ the Food Triangle represents a new organization of food based on an increasing energy density paradigm. However, the Food Triangle can further be expanded to predict the impact of oxidative priority and both nutrient and fiber density in relation to caloric load. When combined with meal frequency, integrated energy expenditure, and fuel partitioning expressed by the respiratory quotient (RQ), our model also offers a novel explanation for chronic overnutrition and the cause of excess body fat accumulation.

In this short review, we will discuss four main points: (i) nutrition is not an emergency; (ii) the Food Triangle predicts oxidative priority; (iii) the chronically fed state is the antithesis of dietary restriction (DR) and counters the favorable metabolic effects of DR demonstrated in longevity research; and (iv) exercise-induced shifts in RQ disrupt fat disposal and portend an unintentional cascade of feeding events.

\section{Calorie In, Calorie Out}

One of the original tenants of human metabolism is that ingested food can be quantified as energy exchange units based on biological energetics and associated waste heat. Throughout the second half of the 19th century and an early part of the 20th century, researchers worked carefully to define this exchange equivalency, or digestive efficiency. ${ }^{2-6}$ Ingested food is broken down into components of energy that are stored, burned, or eliminated in waste. By careful comparison of bomb calorimeter data for various foods with measurements of heat and respiration components in the hours following meals, Carl von Voit, Max Rubner, Max Pettenkofer, Wilbur Atwater, Francis Benedict, and others calculated the average energy conversions for protein, carbohydrate, fat, and alcohol. ${ }^{5-10}$ While it may be true that isocaloric foods are not always isometabolic, food caloric intake minus heat dissipated, respiration, and those calories eliminated as fecal and urine waste must equal zero.

While it may appear that certain calories dominate fat loss and gain, the discrepancy is generally attributed to an oversimplification of energy accounting. With an exception of rare genetic disorders, obesity is largely caused by excessive food intake, with a lesser contribution from physical inactivity due to the tendency to increase calorie consumption during exercise. ${ }^{411}$ However, the phenomenon of an acquired appetite that dominates instinctual eating cues has been recognized since the time of Hippocrates ${ }^{12}$ and the mechanisms involved in leading some people to overeat while leading others to reach a natural balance between hunger and weight remain unresolved. ${ }^{13,14}$ Obesity is not common in the animal kingdom, with the exception of animals (e.g., pets) we overfeed or when excess calories are unnaturally readily available. Moreover, in a calorically scarce environment, a desire to overconsume is not a trait of negative selection and may in fact assert positive benefits. As we describe below, the tendency to store the most energy dense portion of a meal (i.e., fat) may also be explained in terms of an adaptive advantage.

\section{Thermodynamics of Overnutrition}

While it is arithmetically convenient to focus on a daily calorie surplus or deficit, the specific substrate or nutrient utilized, along with energy increases from basal requirements due to diet, activity, and the environment, must be examined on a shorter time scale for a more accurate representation of fatty acid accumulation or oxidation. Figure 1 illustrates calorie input and disposal for a typical day using 1-hr time intervals with the indicated duration, frequency, and overlap of primary energy components. Daily total energy expenditure (TEE) is a composite of basal metabolic rate (BMR), activity, exercise, dietary-induced thermogenesis (DIT), and environmentally-induced thermogenesis (EIT). Experimentally, BMR is measured in the fasted state upon waking in a dark room. However, BMR is often used synonymously with resting metabolic rate (RMR), which typically is measured less stringently and requires only fasting and the absence of physical activity, typically $4 \mathrm{hr}$ before the test. ${ }^{15}$ Experimental tests for both BMR and RMR are normally $15-20 \mathrm{~min}$ in duration, and the results extrapolated over a 24-hr period of time. ${ }^{15}$

Early calorimeter experiments carefully measured the heat emitted from a thermally isolated room yielding direct calorimetry measurements over hours and even days. ${ }^{16}$ Later, in part, for practical purposes, most researchers

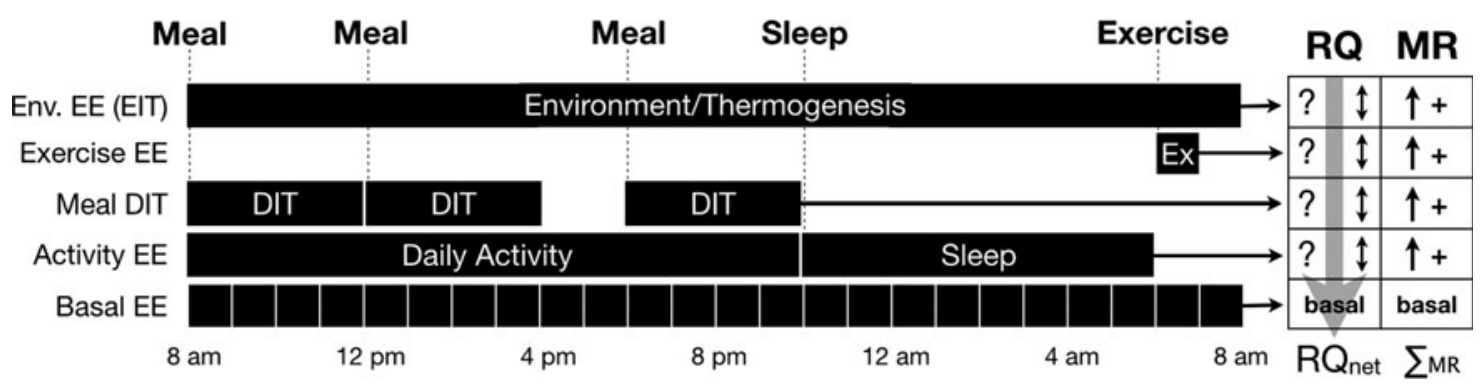

FIG. 1. BMR modification and associated impact on fat oxidation. For each 1-hr interval during a 24-hr period of time, both the MR and RQ must be evaluated to accurately calculate net loss/gain of a specific substrate (e.g., fat). While feeding, activity, and environment may all increase BMR, RQ is dynamic (not discrete for each activity) and acts on the instantaneous total MR. If the largest MR periods occur during times of highest RQ, stored fat is preserved. Use of an average or predicted metabolic rate over a 24-hr period of time compared to calories actually ingested is insufficient to accurately predict substrate gain/loss. BMR, basal metabolic rate; DIT, dietary-induced thermogenesis; EE, energy expenditure; MR, metabolic rate; RQ, respiratory quotient. 
turned to measuring carbon dioxide $\left(\mathrm{CO}_{2}\right)$ produced and oxygen $\left(\mathrm{O}_{2}\right)$ consumed to give an indirect calorimetry measurement of the heat evolved from respiration. The first systematic investigation of the gross energy content of food is credited to Rubner in Germany and Atwater in the United States. ${ }^{7}$ By comparing indirect calorimetry of subjects with a growing database of direct bomb calorimetry of more than 4000 analyses of 1360 different food items, Atwater improved on Rubner's earlier work and created a range of factors and coefficients representing energy availability and digestibility of foodstuffs to delineate their useful calorie content. ${ }^{17}$ However, the oversimplified and generalized notion of energy storage being a consequence of "calories in and calories out," often interpreted as diet and exercise, fails to capture the more subtle thermodynamics of energy storage and disposal, particularly waste heat. Moreover, the human body is not a perfect engine and it is known that the energy liberated from the combustion of food is not identical to the energy available to the body from the consumption of food. ${ }^{18}$ This concept, known as "metabolizable energy," is the difference between the gross energy of consumed food measured by bomb calorimetry and the energy contained in the feces and urine. ${ }^{19}$

To address the dynamic nature of metabolism, the RQ must be factored into this composite metabolic summary. $\mathrm{RQ}$ can be estimated by the respiratory exchange ratio (RER), or the ratio of $\mathrm{CO}_{2}$ produced and $\mathrm{O}_{2}$ consumed during respiration, and can be directly related to the individual substrate being oxidized, whether it is protein, carbohydrate, fat, or alcohol. ${ }^{20} \mathrm{~A}$ general stoichiometric solution for protein, carbohydrate, fat, alcohol, and other less abundant carbon sources in the diet such as acetate and ketone bodies is shown in Fig. 2. The significance of the RER measurement is the ability to use it to estimate the RQ of a mixture of fuel sources (i.e., a typical meal of mixed macronutrients). ${ }^{15}$ Generally, lipids have an RQ of $\sim 0.7$ and carbohydrates have an RQ of $\sim 1.0$.
The RQ of alcohol is slightly lower than lipid at $\sim 0.67$, and while the RQ of amino acids range from 0.6 to 1.17 , the average is $\sim 0.84$. In the case of proteins, since amino acids are not completely oxidized, urine and fecal urea is collected over a 24-hr period to calculate protein oxidation; this value is then subtracted from RQ measurements to give nonprotein RQ (npRQ). ${ }^{15}$ Fortuitously, because the RQ values of proteins generally fall in the middle of the carbohydrate/fat range, indirect calorimetry gives a relatively accurate quantitative snapshot of carbohydrate/fat energy partitioning without nitrogen balance. ${ }^{15}$ For more complete and extensive assessments of energy partitioning, the npRQ is used.

For an accurate interpretation of energy homeostasis, the importance of RQ cannot be overemphasized. One must consider not only the quantity of each ingested macronutrient but also, more importantly, how these fuels are stored and utilized. A surplus or deficit of fat cannot be calculated if one only considers a 24-hr extrapolation (TEE) of a 15min measurement (BMR/RMR) and compares the resulting total predicted activity output with actual calories consumed unless it is also accurately known how the macronutrients are partitioned as fuel throughout the day.

Importantly, RQ captures the percentage rise and fall of fat utilization driven by diet, activity, and environment. And, by combining RQ with TEE, it is evident that the utilization and storage of fat are most relevant to weight gained or lost; this can be represented mathematically as follows:

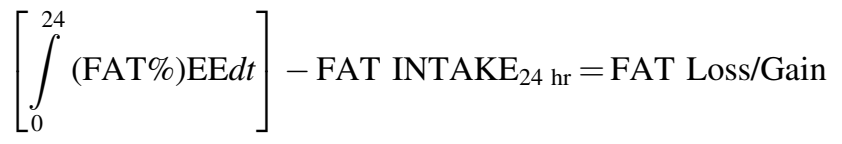

Despite numerous studies demonstrating that de novo lipogenesis from carbohydrates does not significantly

A General Oxidation Stoichiometry Solutions:

\begin{tabular}{|c|c|c|c|c|c|c|}
\hline & C & $\mathbf{H}$ & 0 & $\mathbf{S}$ & $\mathbf{N}$ & $\mathbf{R Q}$ \\
\hline Alanine & 3 & 7 & 2 & & 1 & 0.83 \\
\hline Arginine & 6 & 14 & 2 & & 4 & 0.73 \\
\hline Asparagine & 4 & 8 & 3 & & 2 & 1.00 \\
\hline Aspartic Acid & 4 & 7 & 4 & & 1 & 1.17 \\
\hline Cysteine & 3 & 7 & 2 & 1 & 1 & 0.56 \\
\hline Glutamine & 5 & 10 & 2 & & 2 & 0.80 \\
\hline Glutamic Acid & 5 & 9 & 4 & & 1 & 1.00 \\
\hline Glycine & 2 & 5 & 2 & & 1 & 1.00 \\
\hline Histidine & 6 & 9 & 2 & & 3 & 0.90 \\
\hline Isoleucine & 6 & 13 & 2 & & 1 & 0.73 \\
\hline Leucine & 6 & 13 & 2 & & 1 & 0.73 \\
\hline Lysine & 6 & 14 & 2 & & 2 & 0.71 \\
\hline Methionine & 5 & 11 & 2 & 1 & 1 & 0.60 \\
\hline Phenylalanine & 9 & 11 & 2 & & 1 & 0.85 \\
\hline Proline & 5 & 9 & 2 & & 1 & 0.82 \\
\hline Serine & 3 & 7 & 3 & & 1 & 1.00 \\
\hline Threonine & 4 & 9 & 3 & & 1 & 0.88 \\
\hline Tryptophan & 11 & 12 & 2 & & 2 & 0.87 \\
\hline Tyrosine & 9 & 11 & 3 & & 1 & 0.89 \\
\hline Valine & 5 & 11 & 2 & & 1 & 0.75 \\
\hline Average & & & & & & 0.84 \\
\hline
\end{tabular}

B RQ $=\mathrm{CO}_{2}$ Produced $/ \mathrm{O}_{2}$ Consumed

\begin{tabular}{|c|c|c|c|c|c|c|c|c|c|c|c|c|}
\hline & Molecular Formula & C & $\mathbf{H}$ & O & $\mathbf{S}$ & $\mathbf{N}$ & $\mathbf{A}$ & B & C & D & $\mathbf{E}$ & $\mathbf{R Q}$ \\
\hline Ethanol & $\mathrm{C}_{2} \mathrm{H}_{6} \mathrm{O}$ & 2 & 6 & 1 & - & - & 3 & 2 & 3 & - & - & 0.67 \\
\hline Glucose/Fructose & $\mathrm{C}_{6} \mathrm{H}_{12} \mathrm{O}_{6}$ & 6 & 12 & 6 & - & - & 6 & 6 & 6 & - & - & 1.00 \\
\hline Lactose & $\mathrm{C}_{12} \mathrm{H}_{22} \mathrm{O}_{11}$ & 12 & 22 & 11 & - & - & 12 & 12 & 11 & - & - & 1.00 \\
\hline B-hydroxybutyric Acid & $\mathrm{C}_{4} \mathrm{H}_{8} \mathrm{O}_{3}$ & 4 & 8 & 3 & - & - & 4.5 & 4 & 4 & - & - & 0.89 \\
\hline Acetoacetic Acid & $\mathrm{C}_{4} \mathrm{H}_{6} \mathrm{O}_{3}$ & 4 & 6 & 3 & - & - & 4 & 4 & 3 & - & - & 1.00 \\
\hline Capric Acid & $\mathrm{C}_{10} \mathrm{H}_{20} \mathrm{O}_{2}$ & 10 & 20 & 2 & - & - & 14 & 10 & 10 & - & - & 0.71 \\
\hline Lauric Acid & $\mathrm{C}_{12} \mathrm{H}_{24} \mathrm{O}_{2}$ & 12 & 24 & 2 & - & - & 17 & 12 & 12 & - & - & 0.71 \\
\hline Linoleic Acid & $\mathrm{C}_{18} \mathrm{H}_{32} \mathrm{O}_{2}$ & 18 & 32 & 2 & - & - & 25 & 18 & 16 & - & - & 0.72 \\
\hline Oleic Acid & $\mathrm{C}_{18} \mathrm{H}_{34} \mathrm{O}_{2}$ & 18 & 34 & 2 & - & - & 26 & 18 & 17 & - & - & 0.71 \\
\hline Palmitic Acid & $\mathrm{C}_{16} \mathrm{H}_{32} \mathrm{O}_{2}$ & 16 & 32 & 2 & - & - & 23 & 16 & 16 & - & - & 0.70 \\
\hline Steric Acid & $\mathrm{C}_{18} \mathrm{H}_{36} \mathrm{O}_{2}$ & 18 & 36 & 2 & - & - & 26 & 18 & 18 & - & - & 0.69 \\
\hline Protein (albumin) & ${ }_{72} \mathrm{H}_{112} \mathrm{O}_{22} \mathrm{SN}_{18}$ & 72 & 112 & 22 & 1 & 18 & 77 & 63 & 38 & 1 & 9 & 0.82 \\
\hline
\end{tabular}

\begin{tabular}{|c|c|c|c|c|c|c|c|c|c|}
\hline $\begin{array}{l}\mathrm{A}= \\
\mathrm{B}= \\
\mathrm{C}= \\
\mathrm{D}= \\
\mathrm{E}=\end{array}$ & $\begin{array}{l}X_{1} \\
X_{1}- \\
X_{2} \\
X_{4} \\
X_{5} / 2\end{array}$ & $\begin{array}{l}X_{2} \\
5 / 2 \\
\left.X_{5}\right)\end{array}$ & & $6 X_{4}$ & & & & & \\
\hline $\begin{array}{l}A / b \\
\mathrm{C}_{72}\end{array}$ & $\min$ & Exan & & $\mathrm{O}_{2}$ & & & & & $+\mathrm{SO}_{3}$ \\
\hline H & 0 & $\mathbf{S}$ & $\mathbf{N}$ & $\mathbf{A}$ & B & C & D & $E$ & $\mathbf{R Q}$ \\
\hline 6 & 1 & - & - & 3 & 2 & 3 & - & - & 0.67 \\
\hline 12 & 6 & - & - & 6 & 6 & 6 & - & - & 1.00 \\
\hline 22 & 11 & - & - & 12 & 12 & 11 & - & - & 1.00 \\
\hline 8 & 3 & - & - & 4.5 & 4 & 4 & - & - & 0.89 \\
\hline 6 & 3 & - & - & 4 & 4 & 3 & - & - & 1.00 \\
\hline 20 & 2 & - & - & 14 & 10 & 10 & - & - & 0.71 \\
\hline 24 & 2 & - & - & 17 & 12 & 12 & - & - & 0.71 \\
\hline 32 & 2 & - & - & 25 & 18 & 16 & - & - & 0.72 \\
\hline 34 & 2 & - & - & 26 & 18 & 17 & $=$ & - & 0.71 \\
\hline 32 & 2 & - & - & 23 & 16 & 16 & - & - & 0.70 \\
\hline 36 & 2 & - & - & 26 & 18 & 18 & - & - & 0.69 \\
\hline 112 & 22 & 1 & 18 & 77 & 63 & 38 & 1 & 9 & 0.82 \\
\hline
\end{tabular}

FIG. 2. Substrate oxidation and RQ. (A) General stoichiometry solutions for various fuel substrates. (B) The cellular $\mathrm{RQ}$ - the ratio of $\mathrm{CO}_{2}$ produced to $\mathrm{O}_{2}$ consumed - for a wide variety of foodstuffs. (C) Individual amino acid RQ values are summarized; the average $\mathrm{RQ}$ for all amino acids is an $\mathrm{RQ}=0.84$. Generally accepted $\mathrm{RQ}$ values for the major macronutrients are protein $(\mathrm{PRO})=0.82 ;$ carbohydrate $(\mathrm{CHO})=1.0$; and fat $(\mathrm{FAT})=0.70$. 
contribute to the increase in whole-body adipose tissue stores found in obesity, ${ }^{21-27}$ the notion that "sugar turns to fat" abounds. Perhaps there is further confusion resulting from the unintented consequences of aggregating wholefood complex carbohydrates with highly refined grains and sugars simply because they share the defining glycosidic bond found in all carbohydrates. Not only does this detract from the important negative metabolic effects that excess simple sugar consumption has on hepatic steatosis and mitochondrial dysfunction but it also obfuscates the role that excess dietary protein (amino acid), alcohol, and carbohydrates play in driving dietary fat storage and interfering in stored adipose disposal through normal metabolic activities during the fasted state.

So, how can generalized notions of metabolism be reframed to provide a more accurate assessment of fat disposal and accumulation? Consider the fasted and inactive BMR during a 24-hr period as shown in Fig. 1. During each hour of fasting, the fat deficit grows and its magnitude is determined by the fat percentage of TEE in each unit time. Upon waking and with nondepleted glycogen stores, a normal fasted RQ is $\sim 0.85$, or $\sim 50 \%$ oxidation both from stored fat and carbohydrate. In this scenario, about half of the expected calorie deficit for the 24-hr TEE is predicted to be from fat. Next, consider added activity and its associated increase in energy expenditure (EE) during the active period along with associated increases in RQ (favoring carbohydrate oxidation) typical with periods of increased physical activity. Note that for each hour of activity-shifted RQ and increased EE, the "new" RQ not only affects the calories expended by the added activity but also impacts the calories that would have been expended by the BMR for that same period. This creates a seemingly paradoxical situation, as it is possible to significantly increase EE with activity and simultaneously decrease fat percentage utilization to a point of diminishing returns when compared to calorie restriction alone.

For example, as illustrated in Fig. 3, assume the BMR for a person is $1800 \mathrm{kcal} /$ day $(75 \mathrm{kcal} / \mathrm{hr})$. One hour of physical activity (i.e., jogging at $5 \mathrm{miles} / \mathrm{hr}$ ) will result in an increase to $\sim 500 \mathrm{kcal} / \mathrm{hr}$ in EE. However, it is the utilization of fat calories (resulting from shifts in RQ in any given time unit) that is more relevant and important than total $\mathrm{EE}$ when it comes to body weight. As demonstrated in many calorimeter experiments, vigorous activity will tend to raise RQ and therefore decrease percent fat utilization during the activity period. ${ }^{9,28,29}$ Alternatively, an individual in the fasted/resting state or during extended caloric restriction will have a decreased RQ, thereby increasing percent fat utilization. ${ }^{30,31}$ Conceptually it might be difficult to equate $1 \mathrm{hr}$ of jogging with a little more than half a teaspoon of olive oil $(\sim 40$
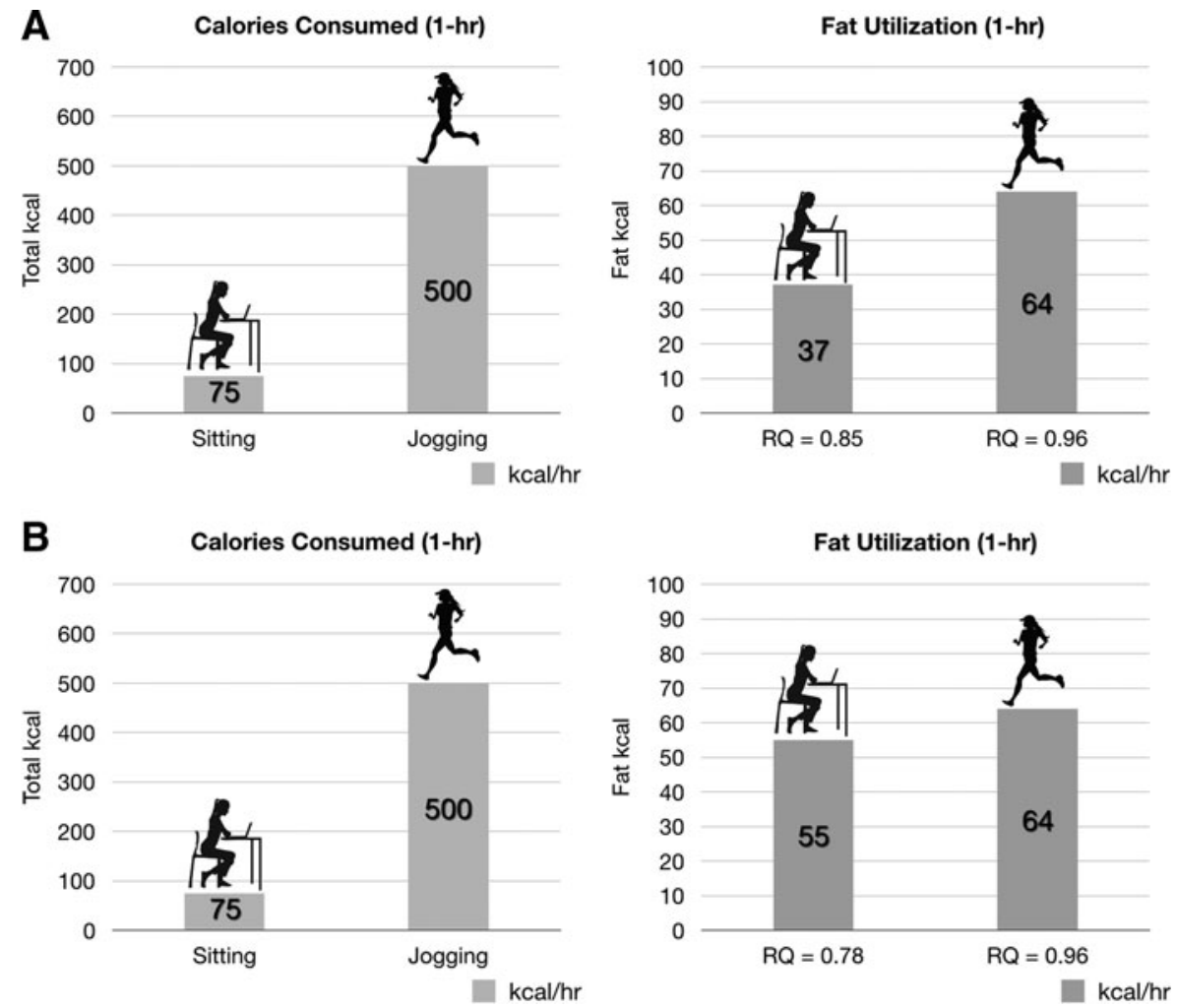

FIG. 3. Fuel utilization and partitioning with physical activity versus calorie restriction. A 1-hr block of time spent sitting is compared to a 1-hr block of time spent jogging. (A) At an RMR of $1800 \mathrm{kcal} / \mathrm{day}$ (a typical individual), a predicted resting RQ of 0.85 (49.3\% fat oxidation) results in $75 \mathrm{kcal} / \mathrm{hr} \mathrm{EE}$ and $37 \mathrm{kcal} / \mathrm{hr}$ fat utilization. During activity, the rise in RQ to 0.96 (12.8\% fat oxidation) results in $500 \mathrm{kcal} / \mathrm{hr} \mathrm{EE}$ and $64 \mathrm{kcal} / \mathrm{hr}$ fat utilization. For comparison, the change in fat utilization between rest and activity equates to slightly more than a $1 / 2$ teaspoon of olive oil ( $\sim 40 \mathrm{kcal} / \mathrm{tsp})$. (B) During times of sustained calorie restriction, resting RQ may drop to an RQ of 0.78 ( $\sim 74 \%$ fat oxidation) due to increased fat utilization, resulting in $\sim 55 \mathrm{kcal} / \mathrm{hr}$ fat utilization. This is a difference of only $9 \mathrm{kcal}$ (less than a $1 / 4$ teaspoon of olive oil) from the 64 $\mathrm{kcal} / \mathrm{hr}$ fat utilization predicted during physical activity in a noncalorie-restricted state. EE, energy expenditure; RMR, resting metabolic rate. 
$\mathrm{kcal} / \mathrm{tsp}$ ) with respect to energy equivalents. However, this observation readily explains why any increase in EE induced by exercise can quickly be overcome by diet. While it is often argued that exercise preserves fat-free mass, when calorie restriction and calorie intake plus exercise are precisely matched, there seems to be parity in loss. ${ }^{11}$ Furthermore, Redman et al. suggest that individuals are genetically or epigenetically programmed for fat loss and accumulation, a "first on-last off" response that may explain why problem areas, such as abdominal fat, are variable among individuals of similar fitness. ${ }^{11}$ Finlayson et al. also suggest that the benefits of exercise may be offset in some people by an "individual reward," in which an increased desire to eat compensates for any calories lost during the activity. ${ }^{32} \mathrm{We}$ propose that determining the exact cause of weight change may be additionally masked by thermodynamic shifts in fuel partitioning through a complex interaction of activity, calorie source, and environment.

\section{Thermodynamics of Feeding}

Feeding, with associated DIT and oxidative priority, adds another level of complexity to the "is a calorie a calorie?" question. Figure 4 illustrates the impact of meal frequency on the time available to dispose of ingested energy. In the fasted state, metabolic energy is completely sourced from body stores. If the fast continues, glycogen stores will eventually be depleted and a shift to fat oxidation will ensue. ${ }^{33}$ Fatty acid-derived ketones can not only contribute to metabolic activity but also provide up to $60 \%-70 \%$ of brain energy needs during long periods of glycogen depletion; blood glucose concentrations are maintained by gluconeogenesis and glucogenic amino acids sourced from protein stores. $^{34,35}$

On feeding, a complex set of digestive processes are initiated, which result in the breakdown of the ingested foodstuffs into their constituent macronutrients (and micronutrients) and their distribution to the tissues. Importantly, by considering the fed and fasted state in a more general conceptual model, the problem that may unfold through chronic overnutrition becomes evident. As each successive meal is added, it disrupts the fasted state and obligates the body to take action on the newly ingested fuel. And although each meal is associated with a 4-6-hr postprandial increase in metabolic rate ${ }^{36}$ the fate of the ingested fuel is discrete as it will be either metabolized, stored, eliminated, or a combination thereof. All calories ingested must ultimately meet one of these three ends. Since meals consist of a mixture of macronutrients, the logical question centers on the regulation of fuel partitioning after a meal: how does the body decide which fuel to utilize, eliminate, or store?

\section{DIT and Oxidative Priority}

Prentice and colleagues addressed the issue of fuel partitioning with their model of oxidative priority, or oxidative hierarchy, based on individual macronutrient storage (Fig. 5). ${ }^{37-44}$ Conceptually, to better understand the fate of the molecular components of food as they begin to leave the digestive tract, it may be useful to put aside the popular food labeling and macronutrient organization scheme of protein, carbohydrate, and fat, and recognize that whole foods, especially entire meals, are mixtures. Complex carbohydrates and simple sugars are broken down to monosaccharides, proteins into constituent amino acids, and lipids mobilized through chylomicron transport. Eating thus results in a postprandial rise in monosaccharide (glucose), amino acid, and lipid blood levels, during which the body attempts to normalize their concentrations by one of the three strategies: utilization, storage, or elimination. Importantly, when storage is limited or impossible, then two choices remain: utilize or eliminate.

For example, following the ingestion of a protein-rich meal, a relatively larger increase in DIT is observed in the postprandial state compared to a carbohydrate-rich meal since amino acids have no significant inherent storage depot; the body essentially transforms excess energy into waste heat. Although the postprandial rise in metabolism following a protein-rich meal may be considered advantageous and a way to mitigate weight gain or even lose weight, little if any of this excess energy is sourced from stored adipose tissue. As demonstrated with the increase in metabolic rate with physical activity, it is possible and even expected that increases in metabolism to dispose of excess calories ingested with a protein-rich meal may actually cause a decrease in stored adipose tissue utilization. An equally important consideration is the following: not only may dietary fat be stored at a higher rate in the presence of macronutrients with a higher oxidative priority but also overall fat oxidation rates may be decreased by shifts in fuel partitioning. ${ }^{45}$
FIG. 4. Fed and fasted state versus meal frequency. (A) Different meal frequencies and their effects on the fed/fasted state. (B) Postprandial fluctuations in plasma macronutrient levels based on meal frequencies.

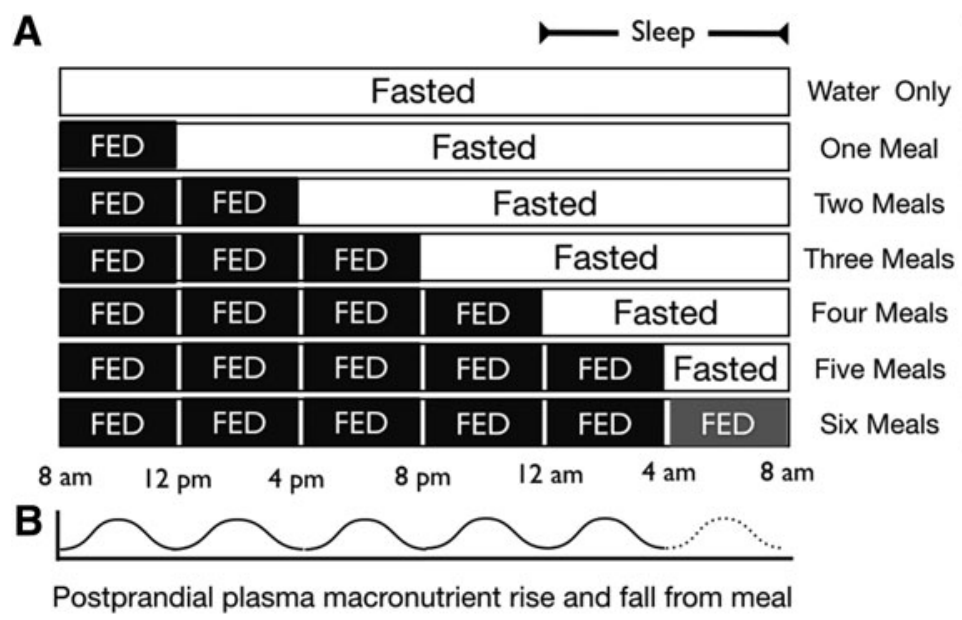

Fed $\quad$ Fasted

\begin{tabular}{|c|c|}
\hline 0 & 24 \\
\hline 4 & 20 \\
\hline 8 & 16 \\
\hline 12 & 12 \\
\hline 16 & 8 \\
\hline 20 & 4 \\
\hline 24 & 0 \\
\hline
\end{tabular}




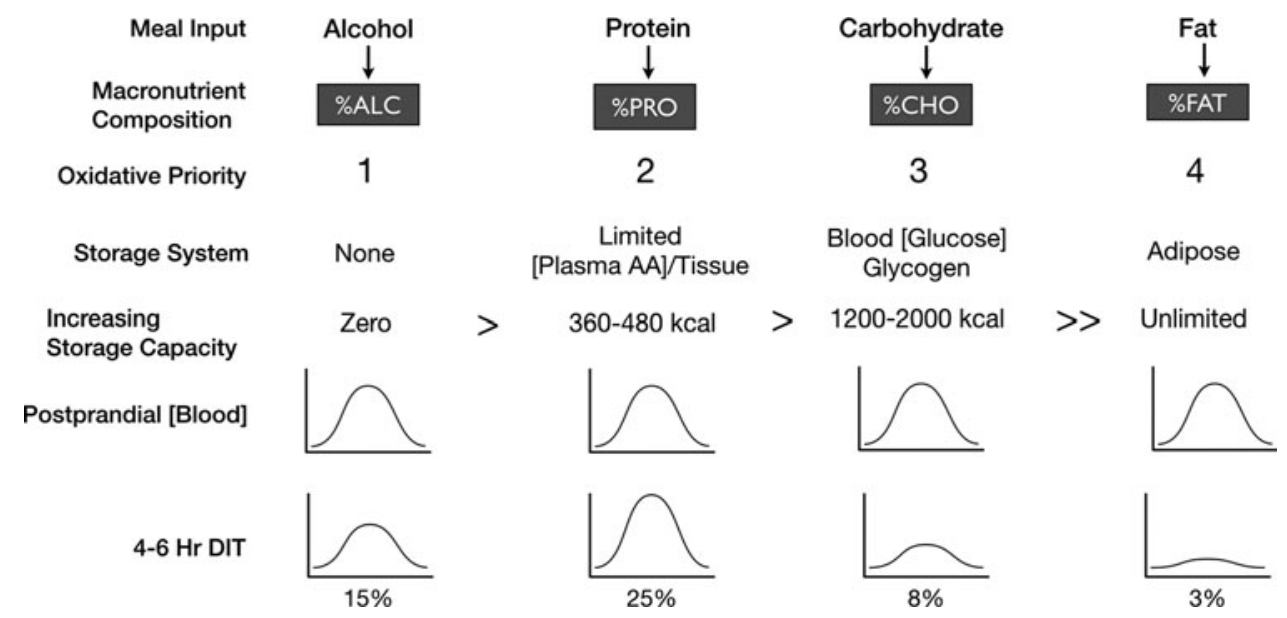

FIG. 5. Oxidative priority of macronutrient disposal. An oxidative prioritization of macronutrients predicts the partitioning hierarchy based on the inverse relationship of storage capacity. Not all macronutrients can be stored at the same level. For example, alcohol has no long-term storage capacity, while fat has a relatively unlimited capacity. While the postprandial DIT rise is highest for protein and lowest for fat, these metabolic increases do not necessarily reflect utilization of stored energy reserves and are rather better explained by the need to mitigate postprandial rises in blood nutrient levels. In nearly all cases, postprandial blood analyte levels that increase due to meals normalize within 4-6 hr as the postabsorptive state is reached. ALC, alcohol; CHO, carbohydrate; DIT, diet-induced thermogenesis; FAT, fat; PRO, protein

Conversely, a greater thermogenic response to food may not always cause excess stored energy reserves to be burned. This concept is demonstrated by data showing the effects of glucose and ethanol administration directly through intravenous infusion. ${ }^{45}$ Whereas ethanol and glucose infusions have no significant impact on overall RMR, ethanol alone suppresses fat oxidation by $87 \%$. Importantly, a glucose infusion following ethanol predictably increases carbohydrate oxidation by $249 \%$ and further suppresses fat oxidation to almost nil for $90 \mathrm{~min}$, with only a slow rise in fat oxidation thereafter; in fact, the total 4-hr integrated oxidation of fat following an ethanol-then-glucose infusion is suppressed by $79 \%$.

Returning to the concept of meal frequency and mixedmeal oxidative priority, one can translate these results to what occurs when an individual consumes a wine, cheese, and cracker hors d'oeuvre. The post-hors d'oeuvre rise in alcohol and glucose concentrations actually suppresses fat oxidation and promotes storage of the dietary fat from the meal. As such, one can easily understand how body fat increases over time; the homeostatic drive to normalize postprandial rises in blood nutrient levels offers a novel conceptual framework that predicts fat accumulation.

\section{Adaptive Thermogenesis}

An additional element that influences the body's metabolism is the overall environment-particularly mild cold stress. ${ }^{46-49}$ In contrast to physical activity that increases RQ, the body's environment can induce the opposite effect. ${ }^{29,50}$ For example, long periods of mild cold stress from cooler ambient temperatures can induce nonshivering thermogenesis, reducing RQ (favoring fat oxidation) ${ }^{51}$; this, simultaneously, increases fasted/resting EE and may lead to an overall increased fat deficit.

Specifically, the activation of brown adipose tissue (BAT) increases mitochondrial heat production in skeletal muscle cells, ${ }^{50,52-54}$ at least, in part, by the upregulation of perox- isome proliferator-activated receptor- $\gamma$ coactivator (PGC)$1 \alpha$-which is induced by low caloric intake or mild cold stress. $^{52,53,55-58}$ Why PGC- $1 \alpha$ is upregulated in response to both low caloric intake and mild cold stress is yet to be fully elucidated; but, in our "Metabolic Winter Hypothesis,", we postulate that the molecular responses to these two stressors (i.e., caloric restriction and cold temperatures) may have evolved in tandem-both conserving energy in the fasted state and partitioning calories to fat for warmth during times of cold. Furthermore, as reported by both Valdés et al. ${ }^{59}$ and Yang et al. ${ }^{60}$ studying relatively homogeneous genetic populations consuming a comparable diet living at mildly different degrees of latitude, an association exists between ambient temperature and obesity.

In general, a discussion of "calories in and calories out" often includes generalized metabolic rates, DIT, energy associated with physical activity, and even BAT and mild cold stress. However, ultimately, it is the integrated total energy expended and fuel partitioned (metabolic rate and RQ) that determine how much adipose tissue is depleted in a given 24-hr period. During periods of nonglycogen depleted fasting, this might be a 50:50 carbohydrate:fat split (RQ 0.85). In the postprandial/fed state, fat utilization may be significantly reduced; alternatively, during an extended fast (glycogen-depleted ketosis), fat utilization may dominate. Clearly, the simple average metabolic rate summary and ubiquitous focus on metabolic "boosting" diets and exercise are insufficient to explain the thermodynamics of feeding; importantly, they may have an unintended consequence in metabolic rate modification and unanticipated RQ shifts away from fat utilization.

\section{The Food Triangle and Whole-Food Diet Schemes}

As we explained in more detail previously, ${ }^{1}$ the Food Triangle offers a novel way to conceptualize food in a manner that eliminates the traditional macronutrient food 
groupings of protein, carbohydrate, and fat that are in widespread use. The Food Triangle organizes whole food using an energy density paradigm. It recognizes that essential amino acids (i.e., proteins) are not limiting nutrients in any whole-food diet that meets daily energy needs. Rather, vegetable- or animal-sourced amino acids, in excess of daily requirements, along with carbohydrates and fat, all become fuel with oxidative priority given to that which is not readily stored. This organization of energy density permits individuals to address their micronutrient requirements (the apex of the triangle) without driving chronic overnutrition (the bottom vertices of the triangle). These foods become the nutritional foundation of daily meals, rather than the more energy-dense alternatives. They also provide a rich source of phytonutrients and can be eaten in nearly unlimited quantities. It further places emphasis on foods that are increasingly important for healthy gut microbiota.

By utilizing the Food Triangle and combining the effect of fed/fasted periods, dietary- and activity-induced RQ shifts, and oxidative priority, it is possible to predict substrate utilization and how different diet schemes effectively mediate preferential fat disposal (Fig. 6). While the magnitude of the impact of carbohydrate consumption versus fat consumption on fat mass gain has been deliberated for decades, the Food Triangle provides a conceptual framework of the relationship between diet and energy density and suggests that both (i.e., dietary carbohydrates [sugars] and dietary fats) individually and synergistically contribute to fat mass gain. We recognize that the complex interdependent roles of insulin, glucagon, and incretins ${ }^{61,62}$ - in addition to other hormones and regulatory molecules-in both the fasting and postprandial states provide mechanistic insights into how oxidative priority is managed and are not comprehensively addressed in this review.

However, our objective with this essay is not to provide an extensive review of nutritional biochemistry and endocrinology; rather, it is to (1) focus on why social influence and unnatural access to food have created the opportunity for the chronic postprandial state and (2) organize food in an understandable manner that much more readily predicts fat accumulation. This conceptual framework also explains why diets that eliminate one or the other (i.e., diets that eliminate fats but permit carbohydrates or vice versa) might be effective in the short term, but are typically unsuccessful for sustained weight loss when the eliminated food is returned. The apex of the Food Triangle contains phytonutrient/fiberrich, low-calorie foods. Down each descending side of the Food Triangle are foods of increasing energy density separated as primarily fat- and carbohydrate-sourced food. A notable exception is the fats sourced from whole-food plantbased nuts, seeds, and certain fruits (e.g., avocados and coconuts).

If one eats on the right side of the Food Triangle, primarily sourcing energy from whole-food dietary starches and fruits, dietary carbohydrate (beyond that needed to replete glycogen stores) may be disposed of via increased RQ and postprandial EE via DIT. On the contrary, a diet sourced from the left side of the Food Triangle will lead to depleted glycogen stores and eventually induce a ketogenic state, lowering RQ and favoring fat utilization. Unlike excess dietary carbohydrates, which are disposed of through oxidation, excess dietary lipid may be partially eliminated in the feces after incomplete absorption. Each approach may be effective in inducing the calorie deficit required to result in weight loss; but, long-term lifestyle decisions to increase an individual's healthspan are more complex. The Food Triangle thus fundamentally provides a paradigm of healthy eating that extends beyond the caloric component of foodstuffs.

Diets that emphasize the base of the Food Triangleperhaps even as an unintended consequence of what one might call a "balanced meal" - may drive excess fat storage via the mechanisms of oxidative priority described above. And, as shown in Fig. 6, the oxidative priority model portends that the postprandial partitioning and disposal of
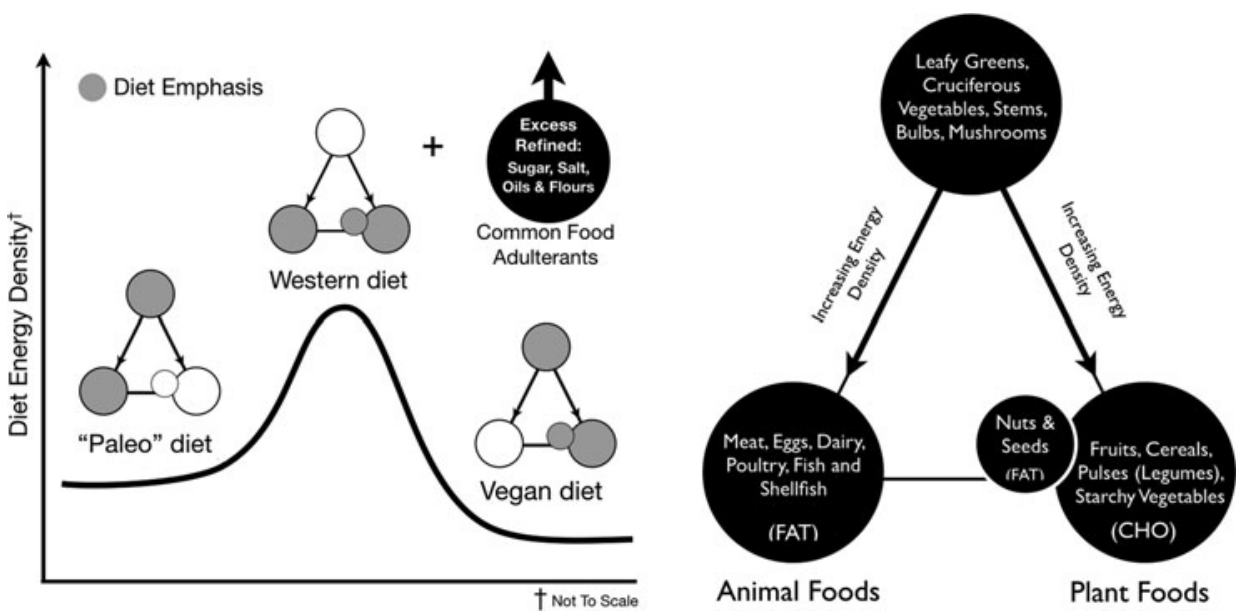

FIG. 6. Energy density of popular diet schemes. Our version of the Food Triangle may be used to compare popular diet schemes for energy density. For example, the relative energy density of a Paleo- versus vegan-style diet, which nearly mirrors the opposite sides of the Food Triangle, is shown. Furthermore, a "Western diet," which is more heavily weighted toward foods at the base of the Food Triangle, is predicted to result in maximum energy accumulation of dietary fat. While not considered part of the whole foods integrated into the Food Triangle, excess refined oil, sugar, and grain (e.g., flour) adulterants may drive any of these diet schemes to unintentional chronic overnutrition. While either side of the Food Triangle is predictive for excess energy, it may also be used to predict overnutrition of dietary amino acids and fats and undernutrition of phytonutrients and dietary fiber. 
foodstuffs from a typical "Western" diet (i.e., a diet emphasizing the base of the Food Triangle) would be obesogenic; this prediction matches the current reality. ${ }^{63}$ Bottom feeding on the base of the Food Triangle, especially with the added consumption of refined grains (e.g., flours), oil, and sugar adulterants, yields a diet in which the most energydense foods are consumed together. Many traditional meal plans from a century or more ago aimed to mitigate economic calorie scarcity, but may have unintentionally created today's widespread food culture-induced bottom feeding (e.g., burger-fries, steak-potatoes, fish-chips, pasta-meat sauce, curry-rice, etc). However, in an environment of unnatural calorie availability, these meals become maladaptive.

This, combined with predictive oxidative priority and a regulated capacity to store excess carbohydrates as glycogen, favors fat storage for later use; unfortunately for most, later never comes. Modern successes in agriculture, reduced food cost, and availability-coupled with current sleep patterns - enable a chronically fed state; and, with excessive meal/snack frequency, it is possible for many individuals to remain in the postprandial/absorptive state for most of the day. This is a period when ingested calorie disposal, not the utilization of energy reserves, is prioritized.

The chronically fed state is further encouraged by the common notion that "nutrition is an emergency" and that frequent feeding is beneficial, despite numerous studies suggesting the beneficial effects of intermittent fasting, diets that mimic fasting, calorie restriction, protein restriction, and prolonged medically supervised water fasts. ${ }^{64}$ However, not only do calorie restriction, alternate day fasting, and periodic fasting have a long history in society, they are the only mechanisms by which life/healthspan has been extended in the laboratory. ${ }^{65-70}$

Researchers and dietitians alike also continue to focus on the "eat meat versus do not eat meat" or "fat versus sugar" debate. We propose this constitutes a false ideological dichotomy that only loosely addresses fat accumulation over time. For example, if one were to follow a strict vegan diet based on the right side of the Food Triangle, thereby eliminating all dietary fat sourced from animal products without limiting oils, refined grains (e.g., flours), or sugar, it is still possible to drive dietary fat storage. Likewise, diets on the left side of the Food Triangle can drive dietary fat storage despite the oft-cited health benefits of maintaining a state of relative ketosis. Why is this so? Because it does not take much dietary carbohydrate, even from healthful sources such as fruits and whole-food low-glycemic starches, to eliminate ketosis and increase the postprandial RQ to favor carbohydrate disposal. In this case, although the dietary carbohydrate is typically viewed as the culprit for fat storage, it is actually the dietary fat component of the meal that is stored. Hall et al. have also reported that consuming an isocaloric low-carbohydrate ketogenic diet when compared to a high-carbohydrate baseline diet is not accompanied by increased body fat loss despite a relatively small increase in EE, or metabolic advantage. ${ }^{71}$

This creates a dietary stalemate; and, while energy components are only one dimension of the Food Triangle, they clearly predict the accumulation of excess adipose tissue when combined with the conceptual model of oxidative priority and hours spent in the fed versus fasted state. The two primary dietary fuels, fats and carbohydrates, essentially exert competing excess energy challenges: dietary carbohydrate calories displace stored fat energy that would have been utilized in the fasted state and dietary fat accumulates, increasing the fat burden that must be used in the future. Clearly, in the chronically fed state, these two energy imbalances favor net accumulation of adipose tissue and in the calorie-limited world this would be an adaptive evolutionary advantage for infrequent feeding opportunities. However, most of the inhabitants of developed countries do not live in a calorie-limited world. Another benefit of returning the discussion back to whole foods using the Food Triangle rather than grouping dietary components in overly general categories of protein, carbohydrates, and fats is that one needs more specificity on each of these macronutrients (e.g., essential vs. nonessential amino acids, simple monosaccharides versus complex carbohydrates and dietary fiber, and saturated and trans-unsaturated fatty acids versus monoand polyunsaturated fatty acids) to study and assess their impacts on health.

\section{Implications for Cardiometabolic Disease}

The increased prevalence of overweight and obesity over the past several decades has paralleled the increased prevalence of cardiometabolic disease. ${ }^{69,72,73}$ Although the correlation between excess weight and cardiometabolic disease is not sufficient to demonstrate causality, most researchers agree the two are tightly linked. Moreover, weight loss via lifestyle factors such as diet and exercise remains a cornerstone to therapy for cardiometabolic disease. However, the relative contribution of diet and exercise to weight loss remains controversial. ${ }^{74,75}$

Furthermore, while potential exercise-induced shifts in eating habits and RQ may lead to less fat utilization in the short term, they should not overshadow the myriad health benefits of exercise or discourage physical activity. However, the option to delay or suspend excessive physical activity during a period of decreased nutrient availability (e.g., during a period of dietary caloric restriction) is a viable alternative to increasing nutrient intake to meet the increased metabolic demands of exercise. Decreased nutrition combined with increased physical activity may unintentionally limit recovery; and, depending on a person's frame, excessive fat mass may increase the risk of injury. However, these issues are mitigated as one approaches normal weight.

From a conceptual framework, it is also important to recognize two important points: (1) although both caloric restriction and exercise may lead to weight loss, the physiological adaptation and responses to each differ dramatically and (2) the weight loss-independent effects of caloric restriction and exercise on risk factors for cardiovascular disease are not additive. ${ }^{76}$ However, because physical inactivity and poor aerobic capacity are independent risk factors for cardiovascular disease, exercise-when safely performed at an appropriate weight-may provide a benefit that cannot be achieved by caloric restriction alone. ${ }^{76}$

As reviewed above, the thermodynamic responses to ingested foodstuffs clearly differ from physical activity. Although many individuals consider exercise to be an antidote to excess calorie intake and that physical activity without changes in dietary intake may lead to significant weight loss, the available data suggest otherwise. ${ }^{1,77-79}$ In general, the negative impact of modern diets exceeds the positive impact of exercise on net weight. And, although the factors that 
lead to obesity and the components of the metabolic syndrome that often (but not necessarily) accompany obesity are not identical, they are nonetheless associated with cardiometabolic disease risk. $^{80-82}$

\section{Conclusion}

From an evolutionary adaptive perspective, it seems unlikely that our ancestors had such easy access to the current socially normal and excessive meal frequency and calorie density. Although periods of fasting for days or perhaps even weeks may appear socially extreme today, they are tolerable $\mathrm{e}^{83-88}$ and were likely imperative to survive in an environment that historically humans had little to no control over. Moreover, seasonal and circadian zeitgebers exert strong feedback mechanisms on cellular and whole-body function, including effects on nutrient disposal. ${ }^{89-95}$ Our "Metabolic Winter Hypothesis" suggests that a healthful existence requires the majority of us to reassess our relationships with food intake, sleep, and the temperature of our environment. ${ }^{1}$ Many observations indicate that DR, mild cold stress, and sleep all appear to have a related mechanistic role of increasing health and longevity and mitigating age-related diseases. ${ }^{96,97}$ One may conceptually frame this by contrasting a metabolic winter (i.e., cool, dark, still, and scarce) with a metabolic summer (i.e., warm, bright, active, and abundant). Added to this framework are the myriad cell signaling pathways and fundamental cellular processes modulated by nutrient availability and nutrient signaling. These are likely part of a larger phenology influencing all animal and plant life, a phenomenon that humans have successfully engineered out of their daily life.

Importantly, using the Food Triangle in place of the traditional categorization of foods as protein, carbohydrate, or fat allows one to more easily identify eating patterns that will likely lead to weight gain. Moreover, food stuffs on the right side of the Food Triangle have components that longevity research shows can extend the healthspan, if not the life span, of mammals and potentially humans ${ }^{98}$ by minimizing essential amino acids to decrease mTOR and GH/IGF-I signaling, while maximizing dietary fiber, vitamins, minerals, and micronutrients such as carotenoids, phytosterols, and flavonoids to activate sirtuins and AMPK. ${ }^{99-101}$

If nutrient availability plays a critical role in seasonal environmental signaling, it may raise the question of how various forms of DR impact overall fuel partitioning and disposal. For example, the restriction of methionine-found in high concentrations in animal-based protein diets (the left side of the Food Triangle) and low concentrations in plantbased protein diets (the right side of the Food Triangle) has been associated with increased longevity and improved age-related health. ${ }^{102-104}$ One might also ask the question whether there is a difference in metabolic feedback to a whole food plant-based very low-calorie diet (VLCD) that has restricted nutrients versus the often abundantly supplemented modern VLCDs (e.g., liquid diets). Furthermore, it is unclear from the standpoint of adaptive evolutionary pressure how any human ancestor might have experienced periods of severely scarce calories yet have had access to abundant "supplemental" nutrients.

In closing, over a century ago, Carl von Voit wrote in a memorial tribute to Max Pettenkofer after his death ${ }^{7}$ :
Imagine our sensations as the picture of the remarkable processes of the metabolism unrolled before our eyes, and a mass of new facts became known to us! We found that in starvation protein and fat alone were burned, that during work more fat was burned, and that less fat was consumed during rest, especially during sleep; that the carnivorous dog could maintain himself on an exclusive protein diet, and if to such a protein diet fat were added, the fat was almost entirely deposited in the body; that carbohydrates, on the contrary, were burned no matter how much was given, and that they, like the fat of the food, protected the body from fat loss, although more carbohydrates than fat had to be given to effect this purpose; that the metabolism in the body was not proportional to the combustibility of the substances outside the body, but that protein, which burns with difficulty outside, metabolizes with the greatest ease, then carbohydrates, while fat, which readily burns outside, is the most difficult to combust in the organism.

Indeed, metabolism is a dynamic process subject to many regulators that mediate the fate of ingested calories. Our version of the Food Triangle predicts the oxidative priority of ingested foods and provides a conceptual paradigm for healthy eating supported by health and longevity research. Importantly, the thermodynamics of feeding are also influenced by the fed and fasted states, and exercise-induced shifts in RQ differentially affect nutrient disposal. The typical modern existence in the chronically fed/postprandial state, combined with oxidative priority and the abundance of inexpensive, calorie-dense foods, and an aversion to mild cold stress amalgamate to predict weight gain for the majority of the developed world if current trends continue.

\section{Acknowledgment}

This work received funding support from NIH grant R01 AG028730 to D.A.S.

\section{Disclaimer}

The contents of this article represent the authors' views and do not constitute an official position of the National Institutes of Health or the U.S. Government.

\section{Author Disclosure Statement}

No competing financial interests exist.

\section{References}

1. Cronise RJ, Sinclair DA, Bremer AA. The "metabolic winter" hypothesis: A cause of the current epidemics of obesity and cardiometabolic disease. Metab Syndr Relat Disord 2014;12:355-361.

2. Atwater W. Discussion of the terms digestibility, availability, and fuel value. 12th Annual Report. Storrs. Agricultural Experimental Station. Storrs, Connecticut. 1900:69.

3. Secor SM. Specific dynamic action: A review of the postprandial metabolic response. J Comp Physiol B 2009; 179:1-56.

4. Hall KD, Heymsfield SB, Kemnitz JW, et al. Energy balance and its components: Implications for body weight regulation. Am J Clin Nutr 2012;95:989-994.

5. Rubner M. The Laws of Energy Consumption in Nutrition: DTIC Document; 1968.

6. Benedict FG, Carpenter TM. Food Ingestion and Energy Transformations: With Special Reference to the Stimulating 
Effect of Nutrients. Washington, DC: Carnegie Institution of Washington; 1918.

7. Lusk G. The Elements of the Science of Nutrition. Phliadelphia and London: WB Saunders Company; 1909.

8. DuBois E. Basal Metabolism in Health and Disease. Philadelphia: Lea and Febiger; 1936.

9. Benedict FG, Cathcart EP. Muscular Work: A Metabolic Study with Special Reference to the Efficiency of the Human Body as a Machine Washington, DC: Carnegie Institution of Washington; 1913.

10. Benedict FG, Miles WR, Roth P, et al. Human Vitality and Efficiency Under Prolonged Restricted Diet. Vol. 280. Washington, DC: Carnegie Institution of Washington; 1919.

11. Redman LM, Heilbronn LK, Martin CK, et al. Effect of calorie restriction with or without exercise on body composition and fat distribution. J Clin Endocrinol Metab 2007;92:865-872.

12. Adams F. The Genuine Works of Hippocrates. Vol. 2. London: The Sydenham Society; 1849.

13. Flatt J. Misconceptions in body weight regulation: Implications for the obesity pandemic. Crit Rev Clin Lab Sci 2012;49:150-165.

14. Atwater WO. Food and Diet. Yearbook of Department of Agriculture 1894. Washington DC: Government Printing Office; 1895:357-388.

15. Lighton JR. Measuring Metabolic Rates: A Manual for Scientists. New York: Oxford University Press; 2008.

16. Webb P., Human Calorimeters. Endocrinology and Metabolism Series. Vol. 7. New York: Praeger; 1985.

17. Atwater WO, Woods CD, Bryant AP. The Chemical Composition of American Food Materials. Washington, DC: Government Printing Office; 1906.

18. Buchholz AC, Schoeller DA. Is a calorie a calorie? Am J Clin Nutr 2004;79:899S-906S.

19. Moe PW. Future directions for energy requirements and food energy values. J Nutr 1994;124:1738S-1742S.

20. Richardson HB. The respiratory quotient. Physiol Rev 1929;9:61-125.

21. Hellerstein MK. No common energy currency: De novo lipogenesis as the road less traveled. Am J Clin Nutr 2001; 74:707-708.

22. Hellerstein MK. De novo lipogenesis in humans: Metabolic and regulatory aspects. Eur J Clin Nutr 1999;53: S53-S65.

23. Hellerstein MK, Christiansen M, Kaempfer S, et al. Measurement of de novo hepatic lipogenesis in humans using stable isotopes. J Clin Invest 1991;87:1841-1852.

24. Acheson KJ, Schutz Y, Bessard T, et al. Carbohydrate metabolism and de novo lipogenesis in human obesity. Am J Clin Nutr 1987;45:78-85.

25. Diaz EO, Prentice AM, Goldberg GR, et al. Metabolic response to experimental overfeeding in lean and overweight healthy volunteers. Am J Clin Nutr 1992;56:641-655.

26. Hill JO, Prentice AM. Sugar and body weight regulation. Am J Clin Nutr 1995;62:264S-273S.

27. McDevitt RM, Bott SJ, Harding M, et al. De novo lipogenesis during controlled overfeeding with sucrose or glucose in lean and obese women. Am J Clin Nutr 2001; 74:737-746.

28. Harris JA, Benedict FG. A biometric study of human basal metabolism. Proc Natl Acad Sci USA 1918;4:370373.

29. Bouhlel E., Salhi Z., Bouhlel H., et al. Effect of Ramadan fasting on fuel oxidation during exercise in trained male rugby players. Diabetes Metab 2006;32:617-624.
30. Bryson J, King S, Burns C, et al. Changes in glucose and lipid metabolism following weight loss produced by a very low calorie diet in obese subjects. Int J Obes Relat Metab Disord 1996;20:338-345.

31. Valtueña S, Solà R, Salas-Salvadó J. A study of the prognostic respiratory markers of sustained weight loss in obese subjects after 28 days on VLCD. Int J Obes 1997; 21:267-273.

32. Finlayson G, Caudwell P, Gibbons C, et al. Low fat loss response after medium-term supervised exercise in obese is associated with exercise-induced increase in food reward. J Obes 2011;2011:pii:615624.

33. Gropper S, Smith J. Advanced Nutrition and Human Metabolism. Belmont, CA: Wadsworth Cengage Learning; 2012.

34. Cahill Jr GF. Fuel metabolism in starvation. Annu Rev Nutr 2006;26:1-22.

35. Felig P, Owen OE, Wahren J, et al. Amino acid metabolism during prolonged starvation. J Clin Invest 1969; 48:584-594.

36. McCue M. Specific dynamic action: A century of investigation. Comp Biochem Physiol A Mol Integr Physiol 2006;144:381-394.

37. Westerterp KR. Diet induced thermogenesis. Nutr Metab 2004;1:5.

38. Jebb SA, Prentice AM, Goldberg GR, et al. Changes in macronutrient balance during over-and underfeeding assessed by 12 -d continuous whole-body calorimetry. Am J Clin Nutr 1996;64:259-266.

39. Prentice AM. Alcohol and obesity. Int J Obes 1995;19: S44-S50.

40. Prentice AM. Are all calories equal? In: Cottrell R, ed. Weight Control. London: Chapman \& Hall; 1995:8-33.

41. Stubbs RJ, Harbron CG, Murgatroyd PR, et al. Covert manipulation of dietary fat and energy density: Effect on substrate flux and food intake in men eating ad libitum. Am J Clin Nutr 1995;62:316-329.

42. Shetty PS, Prentice AM, Goldberg GR, et al. Alterations in fuel selection and voluntary food intake in response to isoenergetic manipulation of glycogen stores in humans. Am J Clin Nutr 1994;60:534-543.

43. Prentice AM. Macronutrients as sources of food energy. Public Health Nutr 2005;8:932-939.

44. McDevitt RM, Poppitt SD, Murgatroyd PR, et al. Macronutrient disposal during controlled overfeeding with glucose, fructose, sucrose, or fat in lean and obese women. Am J Clin Nutr 2000;72:369-377.

45. Shelmet JJ, Reichard GA, Skutches CL, et al. Ethanol causes acute inhibition of carbohydrate, fat, and protein oxidation and insulin resistance. J Clin Invest 1988;81: 1137-1145.

46. Jessen C. Temperature regulation in humans and other mammals. Berlin Heidelberg: Springer-Verlag; 2012.

47. Chen KY, Brychta RJ, Linderman JD, et al. Brown fat activation mediates cold-induced thermogenesis in adult humans in response to a mild decrease in ambient temperature. J Clin Endocrinol Metab 2013;98:E1218-E1223.

48. Lee $\mathrm{P}$, Smith S, Linderman J, et al. Temperatureacclimated brown adipose tissue modulates insulin sensitivity in humans. Diabetes 2014;63:3686-3698.

49. Moellering DR, Smith Jr DL. Ambient temperature and obesity. Curr Obes Rep 2012;1:26-34.

50. Wijers SL, Schrauwen P, Saris WH, et al. Human skeletal muscle mitochondrial uncoupling is associated with cold induced adaptive thermogenesis. PLoS One 2008;3:e1777. 
51. Chondronikola M, Volpi E, Børsheim E, et al. Brown adipose tissue activation is linked to distinct systemic effects on lipid metabolism in humans. Cell Metab 2016; 23:1200-1206.

52. Choi CS, Befroy DE, Codella R, et al. Paradoxical effects of increased expression of PGC- $1 \alpha$ on muscle mitochondrial function and insulin-stimulated muscle glucose metabolism. Proc Natl Acad Sci USA 2008;105:19926-19931.

53. Boström P, Wu J, Jedrychowski MP, et al. A PGC1- $\alpha-$ dependent myokine that drives brown-fat-like development of white fat and thermogenesis. Nature 2012;481: 463-468.

54. Harms M, Seale P. Brown and beige fat: Development, function and therapeutic potential. Nat Med 2013;19: 1252-1263.

55. Tan DX, Manchester LC, Fuentes-Broto L, et al. Significance and application of melatonin in the regulation of brown adipose tissue metabolism: Relation to human obesity. Obes Rev 2011;12:167-188.

56. Cypess AM, Lehman S, Williams G, et al. Identification and importance of brown adipose tissue in adult humans. N Engl J Med 2009;360:1509-1517.

57. van Marken Lichtenbelt WD, Vanhommerig JW, Smulders N., et al. Cold-activated brown adipose tissue in healthy men. N Engl J Med 2009;360:1500-1508.

58. Handschin C, Spiegelman BM. Peroxisome proliferatoractivated receptor $\gamma$ coactivator 1 coactivators, energy homeostasis, and metabolism. Endocr Rev 2006;27:728-735.

59. Valdés S, Maldonado-Araque C, García-Torres F, et al. Ambient temperature and prevalence of obesity in the Spanish population: The Di@bet.es study. Obesity 2014; 22:2328-2332.

60. Yang HK, Han K, Cho J-H, et al. Ambient temperature and prevalence of obesity: A nationwide population-based study in Korea. PLoS One 2015;10:e0141724.

61. Barber TM, Begbie H, Levy J. The incretin pathway as a new therapeutic target for obesity. Maturitas 2010;67: 197-202.

62. Kim W, Egan JM. The role of incretins in glucose homeostasis and diabetes treatment. Pharmacol Rev 2008; 60:470-512.

63. World Disasters Report 2011. Focus on Hunger and Malnutrition. In: Knight L (ed). Geneva: International Federation of Red Cross and Red Crescent Societies; 2011: 251.

64. Brandhorst S, Choi IY, Wei M, et al., A periodic diet that mimics fasting promotes multi-system regeneration, enhanced cognitive performance, and healthspan. Cell Metab 2015;22:86-99.

65. Schultz MB, Sinclair DA. When stem cells grow old: Phenotypes and mechanisms of stem cell aging. Development 2016;143:3-14.

66. Guarente L. Calorie restriction and sirtuins revisited. Genes Dev 2013;27:2072-2085.

67. Guarente L. The resurgence of NAD+. Science 2016;352: 1396-1397.

68. Pijl H. Longevity. The allostatic load of dietary restriction. Physiol Behav 2012;106:51-57.

69. Muoio DM, Neufer PD. Lipid-induced mitochondrial stress and insulin action in muscle. Cell Metab 2012;15: 595-605.

70. Trepanowski JF, Canale RE, Marshall KE, et al. Impact of caloric and dietary restriction regimens on markers of health and longevity in humans and animals: A summary of available findings. Nutr $J$ 2011;10:107.
71. Hall KD, Chen KY, Guo J, et al., Energy expenditure and body composition changes after an isocaloric ketogenic diet in overweight and obese men. Am J Clin Nutr 2016; 104:324-333.

72. Weiss R, Bremer AA, Lustig RH. What is metabolic syndrome, and why are children getting it? Ann N Y Acad Sci 2013;1281:123-140.

73. Bremer AA, Mietus-Snyder M, Lustig R.H. Toward a unifying hypothesis of metabolic syndrome. Pediatrics 2012;129:557-570.

74. Prentice AM, Jebb SA. Obesity in Britain: Gluttony or sloth? BMJ 1995;311:437-439.

75. Katz D. Unfattening our children: forks over feet. Int $J$ Obes 2011;35:33-37.

76. Weiss EP, Albert SG, Reeds DN, et al. Effects of matched weight loss from calorie restriction, exercise, or both on cardiovascular disease risk factors: A randomized intervention trial. Am J Clin Nutr 2016;104:576-586.

77. Pontzer H, Raichlen DA, Wood BM, et al. Huntergatherer energetics and human obesity. PLoS One 2012;7: e40503.

78. Lefevre M, Redman LM, Heilbronn LK, et al. Caloric restriction alone and with exercise improves CVD risk in healthy non-obese individuals. Atherosclerosis 2009;203: 206-213.

79. Larson-Meyer DE, Heilbronn LK, Redman LM, et al. Effect of calorie restriction with or without exercise on insulin sensitivity, $\beta$-cell function, fat cell size, and ectopic lipid in overweight subjects. Diabetes Care 2006; 29:1337-1344.

80. Poirier P, Giles TD, Bray GA, et al. Obesity and cardiovascular disease pathophysiology, evaluation, and effect of weight loss. Arterioscler Thromb Vasc Biol 2006;26: 968-976.

81. Bastien M, Poirier P, Lemieux I, et al. Overview of epidemiology and contribution of obesity to cardiovascular disease. Prog Cardiovasc Dis 2014;56:369-381.

82. Galassi A, Reynolds K, He J. Metabolic syndrome and risk of cardiovascular disease: A meta-analysis. Am J Med 2006;119:812-819.

83. Bouhlel E, Shephard RJ. Optimizing Physical Performance During Fasting and Dietary Restriction: Implications for Athletes and Sports Medicine. Boca Raton, FL: CRC Press; 2015.

84. Goldhamer AC, Klaper M, Foorohar A, et al. Water-only fasting and an exclusively plant foods diet in the management of stage IIIa, low-grade follicular lymphoma. BMJ Case Rep 2015:pii:bcr2015211582.

85. Safdie FM, Dorff T, Quinn D, et al. Fasting and cancer treatment in humans: A case series report. Aging (Albany NY) 2009;1:988-1007.

86. Goldhamer AC, Lisle DJ, Sultana P, et al., Medically supervised water-only fasting in the treatment of borderline hypertension. J Altern Complement Med 2002;8:643650.

87. Goldhamer AC. Initial cost of care results in medically supervised water-only fasting for treating high blood pressure and diabetes. J Altern Complement Med 2002;8: 696-697.

88. Stewart W, Fleming LW. Features of a successful therapeutic fast of 382 days' duration. Postgrad Med J 1973; 49:203-209.

89. Eckel-Mahan KL, Patel VR, de Mateo S, et al. Reprogramming of the circadian clock by nutritional challenge. Cell 2013;155:1464-1478. 
90. Sahar S, Sassone-Corsi P. Regulation of metabolism: The circadian clock dictates the time. Trends Endocrinol Metab 2012;23:1-8.

91. Dibner C, Schibler U, Albrecht U. The mammalian circadian timing system: Organization and coordination of central and peripheral clocks. Апnи Rev Physiol 2010; 72:517-549.

92. Figueroa A, Hanzu F, Gomis R. Nutrition and the clock gene. Acta Endo 2015;11:489-491.

93. Kantermann T, Juda M, Merrow M, et al. The human circadian clock's seasonal adjustment is disrupted by daylight saving time. Curr Biol 2007;17:1996-2000.

94. Merrow M, Spoelstra K, Roenneberg T. The circadian cycle: Daily rhythms from behaviour to genes. EMBO Rep 2005;6:930-935.

95. Roenneberg T, Wirz-Justice A, Merrow M. Life between clocks: Daily temporal patterns of human chronotypes. $J$ Biol Rhythms 2003;18:80-90.

96. Prentice AM. Starvation in humans: Evolutionary background and contemporary implications. Mech Ageing Dev 2005;126:976-981.

97. Ramis MR, Esteban S, Miralles A, et al. Caloric restriction, resveratrol and melatonin: Role of SIRT1 and implications for aging and related-diseases. Mech Ageing Dev 2015; 146:28-41.

98. Longo VD, Antebi A, Bartke A, et al. Interventions to slow aging in humans: Are we ready? Aging Cell 2015;14: 497-510.

99. Longo VD, Panda S. Fasting, circadian rhythms, and timerestricted feeding in healthy lifespan. Cell Metab 2016; 23:1048-1059.
100. Mercken EM, Carboneau BA, Krzysik-Walker SM, et al. Of mice and men: The benefits of caloric restriction, exercise, and mimetics. Ageing Res Rev 2012;11: 390-398.

101. Hubbard BP, Sinclair DA. Small molecule SIRT1 activators for the treatment of aging and age-related diseases. Trends Pharmacol Sci 2014;35:146-154.

102. Lee BC, Kaya A, Gladyshev VN. Methionine restriction and life-span control. Ann NY Acad Sci 2016;1363:116-124.

103. McCarty MF, Barroso-Aranda J, Contreras F. The lowmethionine content of vegan diets may make methionine restriction feasible as a life extension strategy. Med $\mathrm{Hy}$ potheses 2009;72:125-128.

104. McIsaac RS, Lewis KN, Gibney PA, et al. From yeast to human: Exploring the comparative biology of methionine restriction in extending eukaryotic life span. Ann $N Y$ Acad Sci 2016;1363:155-170.

Address correspondence to: Andrew A. Bremer, $M D, P h D$ Division of Diabetes, Endocrinology and Metabolic Diseases National Institute of Diabetes and Digestive and Kidney Diseases National Institutes of Health 6707 Democracy Boulevard Building 2DEM, Room 6067

Bethesda, MD 20892-5460

E-mail: andrew.bremer@nih.gov 